\title{
Analisis Model Respirasi Dengan Fungsi Temperatur Bergantung Waktu Sebagai Estimasi Respirasi Udang Windu
}

\author{
Bintang Permata Hati, Sutimin \\ Jurusan Matematika, Fakultas MIPA \\ Universitas Diponegoro \\ Kampus Tembalang Semarang 50275 \\ Telp. (024) 7474754 \\ e-mail : sutimin@ undip.ac.id
}

\begin{abstract}
ABSTRAK
Model respirasi sebagai fungsi respirasi diasumsikan bergantung waktu dianalisis untuk menentukan estimasi konsumsi oksigen pada udang windu. Formulasi model respirasi ini dinyatakan berdasarkan pertumbuhan berat udang dan fungsi respirasi. Pertumbuhan berat udang windu dimodelkan dengan persamaaan Von Bertalanffy. Fungsi respirasi dinyatakan dalam temperatur bergantung pada variabel waktu. Analisis model respirasi dilakukan untuk mengetahui konsumsi oksigen oleh udang windu. Melalui bidang fase ditunjukkkan kestabilan model yang menentukan batas ambang konsumsi oksigen terlarut. Simulasi numerik berdasarkan data eksperimen yang untuk mengambarkan konsumsi oksigen udang windu terhadap waktu.
\end{abstract}

Kata kunci: Model respirasi, udang windu, temperatur.

\begin{abstract}
A model respiration as a time-dependent function is analyzed. Here, this model is studied to estimate the oxygen consumption of the shrimp (Penaeus monodon). Respiration model formulation is expressed by the growth of shrimp weight and respiratory function. The growth model of the shrimp (Penaeus monodon) weight is modeled by Von Bertalanffy equation, while the respiratory function is a function of temperature which depends on time. The stability of the model is studied to obtain the phase portrait in the phase plane. The simulation result based on experiment is presented to show the behavior of the respiration model of shrimp in interval time.

Keywords: Respiration model, schrimp, temperature
\end{abstract}

\section{Pendahuluan}

Dalam ekosistem perairan tambak udang windu, salah satu factor yang menentukan kualitas air adalah kosentrasi oksigen terlarut dalam perairan tambak. Kadar oksigen terlarut (DO) yang cukup di perairan tambak udang windu sangat diperlukan populasi udang windu selama aktivitas respirasi 
(pernafasan). Kekurangan oksigen di dalam perairan tambak dapat mengganggu kelangsungan hidup udang dan sebagai akibat dapat mempengaruhi kematian udang itu sendiri. Kadar oksigen terlarut dalam perairan tambak harus dijaga agar tetap sesuai dengan kebutuhan udang windu [2], [3].

Salah satu faktor yang mempengaruhi perubahan konsentrasi oksigen terlarut adalah temperatur. Hampir semua organisme yang hidup di perairan termasuk udang windu sangat peka terhadap perubahan temperatur. Pada daerah di perairan tropic perubahan temperatur bisa dikatakan berubah secara periodik yang tidak berubah secara drastis. Sehingga udang windu sangat cocok hidup di perairan daerah tropik. Temperatur yang tinggi menyebabkan kemampuan air untuk mengikat oksigen menjadi menurun, sehingga kandungan oksigen dalam air menjadi menurun pula, padahal kebutuhan organisme terhadap oksigen justru semakin meningkat. Hal ini mempengaruhi aktivitas hewan-hewan akuatik (udang windu) yang hidup di dalam perairan tersebut.

Bertolak dari pemikiran tersebut, dalam makalah ini dilakukan suatu analisis model respirasi yang akan digunakan untuk mengestimasi konsumsi oksigen udang windu sehingga dapat diketahui dinamika dan batas konsentrasi oksigen yang dapat dikonsumsi oleh udang windu.

\section{Pemodelan}

\section{Model Pertumbuhan Berat Udang Windu}

Berat udang dianggap sebagai suatu fungsi tak linier terhadap panjangnya. Sehingga model pertumbuhan berat udang berkaitan dengan model pertumbuhan panjang. Model berat udang menurut [1], [4] dan [6], dalam hubungannya dengan panjang dinyatakan oleh,

$$
W(t)=b L(t)^{3}
$$

dengan $W(t)$ : berat pada waktu $t, L(t)$ : panjang pada waktu $\mathrm{t}$ dan $b$ : konstanta yang harus ditentukan berdasarkan data. Dari persamaan (1), dapat diturunkan suatu model pertumbuhan berat udang yang dinyatakan dengan

$$
\frac{d W(t)}{d t}=b^{\frac{1}{3}} a W(t)^{\frac{2}{3}}-\beta W(t)
$$

Jika diberikan syarat awal $\mathrm{W}\left(\mathrm{t}_{0}\right)=0$, maka diperoleh solusi khusus dari persamaan (2) yaitu:

$$
W(t)=b\left(\frac{a}{\beta}\right)^{3}\left(1-e^{-\frac{\beta}{3}\left(t-t_{0}\right)}\right)^{3}
$$

dengan $b\left(\frac{a}{\beta}\right)^{3}=W_{\infty}$ dan $\frac{\beta}{3}=k$. Dengan pemisalan ini, maka persamaan

(3) dapat ditulis menjadi, 


$$
W(t)=W_{\infty}\left(1-e^{-k\left(t-t_{0}\right)}\right)^{3}
$$

Dari persamaan (4) ini menunjukkan bahwa berat udang pada awalnya naik secara eksponensial kemudian berat udang akan bertambah secara lamban setelah waktu tertentu dan menuju batas ambang (maksimum) dari berat udang.

\section{Fungsi Respirasi Dengan Temperatur Bergantung Waktu}

Pada bagian ini akan menganalisis fungsi respirasi dengan mengasumsikan temperatur bergantung pada waktu. Robert B. Humston dkk. [5] menyatakan bahwa fungsi respirasi dinyatakan oleh,

$$
f_{R}(T)=v^{x} e^{x(1-v)}
$$

dengan,

$$
\begin{aligned}
& f_{R}(T) \quad \text { : fungsi respirasi bergantung temperatur } \\
& v(T) \quad: \frac{R T M-T}{R T M-R T O} \\
& x: \frac{(\ln (R Q) \cdot(R T M-R T O))^{2} \cdot \frac{\left(1+(1+40)^{0.5}\right)^{2}}{\ln (R Q) \cdot(R T M-R T O+2)}}{400} \\
& \mathrm{RQ} \text { : respirasi } \mathrm{Q}_{10}=2.4 \\
& \text { RTM : temperatur maksimum untuk respirasi }\left(=31^{\circ} \mathrm{C}\right) \\
& \text { RTO : temperatur optimum untuk respirasi }\left(=28^{\circ} \mathrm{C}\right)
\end{aligned}
$$

Jika nilai-nilai parameter ini disubstitusikan ke persamaan (5), maka fungsi respirasi dinyatakan sebagai,

$$
f_{R}(T)=\left(\frac{31}{3}-\frac{T}{3}\right)^{0.2} e^{\left(\frac{T}{15}-\frac{28}{15}\right)}
$$

Menurut [2] menyatakan bahwa model temperatur merupakan fungsi harmonis sederhana yang berperiodik terhadap waktu siang dan malam. Oleh karena dalam eksperimen, data yang diukur dalam waktu dua mingguan, di sini diasumsikan parameter waktu ditentukan dalam mingguan. Fungsi temperatur akan dinyatakan dalam bentuk fungsi cosinus dengan frequensi $\omega$ sebagai,

$$
T(t)=A \cos \left(\omega t-\phi_{0}\right)+\bar{T}
$$

dengan :

$T(t) \quad$ : temperatur pada waktu $\mathrm{t}$

A : rentang temperatur maksimum dan minimum

$\omega$ : frekuensi angular

$t$ : waktu dalam mingguan

$\phi_{0}:$ sudut fase awal

$\bar{T}$ : rata - rata temperatur selama dalam penukuran data 
Nilai parameter pada persamaan (7) ditentukan berdasarkan data hasil pengukuran pada tabel 1 . Berdasarkan tabel 1 , diperoleh sebagai berikut:

$$
\begin{aligned}
& \omega=\frac{2 \pi}{\text { periode }}=\frac{2 \pi}{4}=\frac{\pi}{2}, \\
& \bar{T}=\frac{\sum_{i=1}^{n=15} T\left(t_{i}\right)}{n}=27,8^{\circ} \mathrm{C} \\
& \mathrm{A}=\frac{30.3-25.4}{2}=2.45^{\circ} \mathrm{C}
\end{aligned}
$$

Pada saat $t=0$, nilai $T=25,9^{\circ} C$ dan $\phi_{0}=\arcsin (-0,849)=2,58 \mathrm{rad}$. Dengan demikian fungsi temperatur dalam terhadap variabel waktu dinyatakan oleh,

$$
T(t)=2.45 \cos \left(\frac{\pi}{2} t-2,58\right)+27,8^{o}
$$

sehingga

$$
v(t)=1-0.82 \cos \left(\frac{\pi}{2} t-2,58\right)
$$

Dengan mensubstitusikan persamaan (8) dan (9) ke persamaan (5), diperoleh fungsi respirasi bergantung waktu sebagai berikut,

$$
f_{R}(t)=\left(1-0.82 \cos \left(\frac{\pi}{2} t-2,58\right)^{0.2} e^{0.16 \cos \left(\frac{\pi}{2} t-2,58\right)}\right.
$$

Persamaan (10) ini menunjukkan bahwa fungsi respirasi bergantung pada parameter waktu dalam mingguan.

\section{Model Respirasi Udang Windu}

Dengan mengasumsikan bahwa respirasi udang windu dipengaruhi oleh berat rata - rata udang windu dan fungsi respirasi bergantung temperatur. Menurut [5] persamaan model respirasi dinyatakan sebagai berikut:

$$
R(t)=\alpha W(t)^{\lambda} f_{R}(T(t))
$$

dengan :

$R(t) \quad$ : respirasi udang pada waktu $\mathrm{t}$

$W(t) \quad$ : berat rata-rata udang pada waktu $\mathrm{t}$

$f_{R}(T(t))$ : fungsi untuk respirasi bergantung temperatur

$\alpha, \lambda \quad$ : konstanta harus ditentukan berdasarkan data eksperimen

Dari persamaan (4), (7), (8), (9) dan (10), dapat diperoleh persamaan model respirasi bergantung waktu 


$$
R(t)=\alpha\left(W_{\infty}\left(1-e^{-k\left(t-t_{0}\right)}\right)^{3}\right)^{\lambda}\left(\frac{31}{3}-\frac{T(t)}{3}\right)^{0.2} e^{\left(\frac{T(t)}{15}-\frac{28}{15}\right)}
$$

Atau dapat ditulis dalam fungsi waktu

$$
R(t)=\alpha\left(W_{\infty}\left(1-e^{-k\left(t-t_{0}\right)}\right)^{3}\right)^{\lambda}\left(1-0.82 \cos \left(\frac{\pi}{2} t-1.03\right)\right)^{0.2} e^{0.16 \cos \left(\frac{\pi}{2} t-2,58\right)}
$$

Untuk mengetahui dinamik model respirasi ini harus ditentukan nilai parameter $\alpha, \lambda, k$ dan $W_{\infty}$ berdasarkan data eksperimen.

\section{Analisis Model Respirasi}

Dengan menurunkan persamaan (11) terhadap $t$ akan diperoleh model laju respirasi yang dinyatakan sebagai berikut

$$
\frac{d R(t)}{d t}=\lambda R(t)\left(b^{\frac{1}{3}} a\left(\frac{R(t)}{\alpha f_{R}(T)}\right)^{-\frac{1}{3 \lambda}}-\beta\right)
$$

Karena fungsi respirasi $f_{R}(T)$ sebagai fungsi temperatur yang bergantung pada parameter waktu. Untuk menentukan nilai maksimum akan ditentukan berdasarkan temperatur optimum untuk respirasi yaitu pada temperatur $T=28^{\circ} C$ dengan nilai fungsi temperatur $f_{R}(T)=0,98$. Respirasi kritis (maksimum) diperoleh pada saat laju respirasi bernilai nol. Sehingga diperoleh,

$$
\mathrm{R}_{\max }=\left(\frac{a}{\beta}\right)^{3 \lambda} b^{\lambda} \alpha f_{R}(T)
$$

Untuk mengetahui kapan respirasi mencapai maksimum $\left(t=t_{\max }\right)$ yaitu dengan mensubstitusikan nilai $R_{\max }$ ke persamaan (12), diperoleh :

$$
t_{\text {max }}=t_{0}-\frac{\ln \left(1-\frac{a}{b^{\frac{2}{3}} W_{\infty}^{\frac{1}{3}}}\right)}{k}
$$

Laju respirasi maksimum ditentukan dengan menggunakan turunan dari persamaan (14) terhadap $R(t)$ sama dengan nol, sehingga diperoleh

$$
R(t)=\left(\frac{\chi}{\varphi\left(1-\frac{1}{3 \lambda}\right)}\right)^{-3 \lambda}
$$

Persamaan (17) disubstitusikan ke persamaan (14), diperoleh : 


$$
\mid \frac{d R(t)}{d t} \max =\varphi\left(\frac{\chi}{\varphi\left(1-\frac{1}{3 \lambda}\right)}\right)^{1-3 \lambda}-\chi\left(\frac{\chi}{\varphi\left(1-\frac{1}{3 \lambda}\right)}\right)^{-3 \lambda}
$$

dengan $\frac{\lambda b^{\frac{1}{3}} a}{\left(\alpha f_{R}(T)\right)^{-\frac{1}{3 \lambda}}}=\varphi$ dan $\lambda \beta=\varphi$.

Untuk menganalisis kestabilan model respirasi udang windu ini dilakukan melalui analisis trayektori model pada bidang fase. Persamaan (14) ini mempunyai dua titik kesetimbangan, yaitu titik $R_{1} *=0$ dan $R_{2} *=\left(\frac{a}{\beta}\right)^{3 \lambda} b^{\lambda} \alpha f_{R}(T)$. Trayektori persamaan model respirasi pada bidang fase dinyatakan pada Gambar 1,

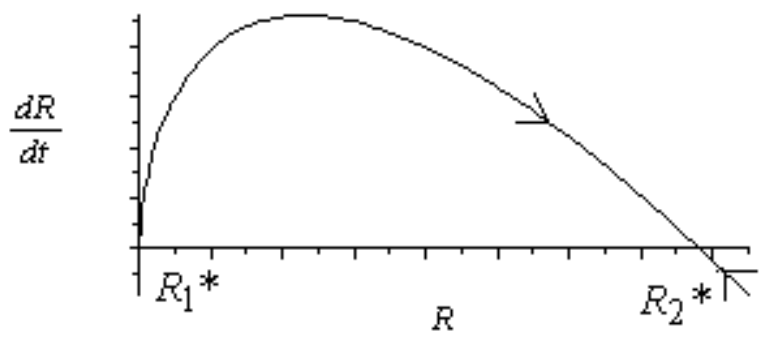

Gambar 1. Trayektori respirasi pada bidang fase

Berdasarkan trayektori pada bidang fase menunjukkan bahwa titik kesetimbangan pertama $R_{1}$ *tidak stabil, sedangkan titik kesetimbangan kedua $R_{2} *$ stabil. Ini menunjukkan bahwa batas ambang konsumsi oksigen oleh udang windu sebesar $\left(\frac{a}{\beta}\right)^{3 \lambda} b^{\lambda} \alpha f_{R}(T)$ yang bergantung pada temperatur.

\section{Simulasi}


Untuk menentukan parameter-parameter dalam persamaan model telah dilakukan eksperimen di Lab. LPWP Undip Jepara, yang diberikan pada tabel 1 berikut.

Tabel 1: Data Respirasi Udang Windu

\begin{tabular}{|c|c|c|c|c|}
\hline $\begin{array}{c}\text { Waktu } \\
\text { Pengukuran }\end{array}$ & $\begin{array}{l}\text { Temperatur } \\
\left({ }^{\circ} \mathrm{C}\right)\end{array}$ & $\begin{array}{c}\text { DO } \\
\text { Awal } \\
\text { (mg/lt) }\end{array}$ & $\begin{array}{c}\text { DO } \\
\text { Akhir } \\
\text { (mg/lt) }\end{array}$ & $\begin{array}{c}\text { DO } \\
(\mathrm{mg} / \mathrm{lt})\end{array}$ \\
\hline \multirow{3}{*}{4} & 25,9 & 5,3 & 5,20 & 0,20 \\
\hline & 25,4 & 5,6 & 5,20 & 0,80 \\
\hline & 25,4 & 6,4 & 4,40 & 4,00 \\
\hline \multirow{3}{*}{6} & 29,0 & 5,0 & 3,70 & 2,60 \\
\hline & 29,2 & 4,9 & 4,20 & 1,60 \\
\hline & 29,1 & 4,5 & 3,40 & 2,20 \\
\hline \multirow{3}{*}{8} & 27,2 & 4,8 & 3,60 & 2,40 \\
\hline & 27,0 & 5,3 & 4,25 & 2,10 \\
\hline & 27,1 & 5,0 & 3,90 & 2,20 \\
\hline \multirow{3}{*}{10} & 30.2 & 4,4 & 3,50 & 1,80 \\
\hline & 30.1 & 5,5 & 4,50 & 2,00 \\
\hline & 30,3 & 5,9 & 4,00 & 3,80 \\
\hline \multirow{3}{*}{12} & 28,2 & 5,1 & 4,00 & 2,20 \\
\hline & 28,3 & 4,8 & 3,10 & 3,40 \\
\hline & 28,2 & 4,9 & 3,40 & 3,00 \\
\hline
\end{tabular}

Simulasi dilakukan untuk mengetahui seberapa baik model yang telah dianalisis dengan data hasil pengukuran. Perhitungan parameter untuk berat udang menggunakan metode Walford. Dari model Von Bertalanffy untuk panjang udang $L(t)=L_{\infty}\left(1-e^{-k\left(t-t_{0}\right)}\right)$ dibawa ke bentuk

$$
L(t)=L_{\infty}\left(1-e^{-k t}\right)+L_{\infty} e^{-k t}
$$

kemudian dapat dibentuk persamaan iterasi berikut ini

$$
L_{t+1}=L_{\infty}\left(1-e^{-k}\right)+L_{t} e^{-k}
$$

Persamaan (19) merupakan persamaan garis lurus, dengan memisalkan $c=L_{\infty}\left(1-e^{-k}\right)$ sebagai intersep, $d=e^{-k}$ sebagai sudut walford. Nilai $c$ dan $\mathrm{d}$ dapat dicari dengan metode kuadrat terkecil melalui perhitungan dengan MAPLE. Dengan demikian nilai parameter $L_{\infty}, k, t_{0}, W_{\infty}$ bisa dicari. Parameter $\alpha$ dan $\lambda$ pada model respirasi, dihitung dengan juga menggunakan metode kuadrat terkecil. Diperoleh $\alpha=1, W_{\infty}=26,6=9, k=0,06 t_{0}=-0.146$, $\lambda=0.4$ dan $f_{R}(T)=0.98$. Simulasi konsumsi oksigen udang windu terhadap waktu berdasarkan estimasi nilai parameter yang membandingkan hasil perhitungan dari model dan data eksperimen disajikan pada Gambar 2 berikut. 


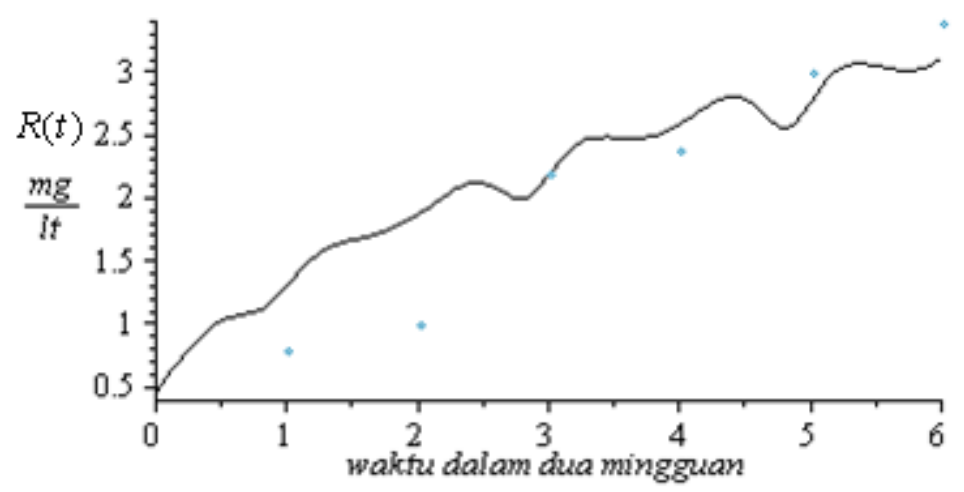

Gambar 2. Konsumsi udang windu per waktu dua mingguan

Berdasarkan simulasi ini dapat dilihat bahwa persamaan model respirasi dengan temperatur bergantung waktu cukup baik dalam mengestimasi konsumsi oksigen udang windu.

\section{Simpulan}

Dalam model respirasi udang windu bergantung waktu memberikan hasil analisis sangat kompleks. Sehingga diperlukan penyederhanaan untuk menentukan kriteria kestabilan solusi titik tetapnya. Perubahan temperatur terhadap waktu merupakan faktor menyebabkan kerumitan dalam analisis.

Berdasarkan hasil analisis kestabilan dapat disimpulkan bahwa model respirasi menunjukkan kestabilan pada saat titik kesetimbangannya bukan nol dan tidak stabil pada titik kesetimbangannya nol. Persamaan model respirasi dengan temperatur bergantung waktu pada udang windu berdasarkan data empiris menunjukkan kecocokan, dalam hal ini model respirasi akan lebih baik jika fungsi untuk respirasi bergantung temperaturnya sebagai fungsi waktu. Model respirasi ini masih perlu dikaji dengan memperhatikan parameter waktu dalam harian. Karena akan memberikan hasil yang lebih baik jika dibanding dengan waktu dalam mingguan.

\section{Ucapan Terima Kasih}

Penulis mengucapkan terimakasih kepada Kementerian Negara Riset dan Teknologi yang telah membiayai proyek ini, melalui program insentif riset dasar dengan nomor kontrak penelitian nomor 41/RD/Insentif/PPK/I/2007.

\section{Daftar Pustaka}


1. Bertalanfy, L. Von, 1938, A Quantiative Theory of Organic Growth (inquires on Growth Law II). Hum. Biol $10181-213$

2. Boyd, C. E, 1991. Water quality and Aertion in Shrimp Farming. Alabama Brimingham Pusblishing Co, Auburn University: Alabama

3. Logan, Dennis T., 1985. Enviromental Variation and Striped Bass Population Dynamics: A Size Dependent Mortality Model. Marine Ecological Research, Inc. Vol 8, No. 1 : 28-38

4. Pauly D. David N., 1980. An Objective Methods for Determining Fish Growth from Length Frequency Data, ICLARM Newsletter 3: 13 - 15

5. Robert Humston, Donald B. Olson and Jerald S. Ault, Behavioral Assumption of Fish Movement and Their Influence on Population Dyamic, Transaction on the American Society, 133, 3024-1328,

6. Sutimin, Sulanjari., 2008, Model Dinamik Pertumbuhan Biomassa Udang Windu, J. Matematika, Vol. 11, No. 2. 
Bintang Permata Hati et al / JMI Vol 9 No 1 2013, pp 29 - 37 